\title{
ROLLING SPECIAL EDITION
}

The I I th International Rolling Conference, IRC 2019, took place in October 2019, in São Paulo, Brazil. The conference happened within ABM Week 2019, the most traditional annual Brazilian Metallurgy conference and within the $56^{\text {th }}$ Rolling Seminar, the oldest seminar held by ABM, the Brazilian Association for Metallurgy, Mining and Materials. In this event, authors representing 23 countries presented 167 papers.

The IRC conference happens every three years. The first edition was in 1985 in Japan. The last two venues were Italy, 2013 and Austria, 20I6. Thanks to this long series of continuous events, IRC has become one of the most important conferences in the field of rolling of flat and long products of both ferrous and nonferrous alloys. In 2019 Brazil hosted IRC in recognition to the efforts of $A B M$ and the intense work of its technical and scientific membership.

IRC 2019 was a great success. High-level technical works were presented giving the opportunity for in-depth and very interesting discussions in the area of rolling. As a result of the remarkable technical level of papers and discussions, ABM decided to edit a special issue within its traditional technical journal, TMM. Renowned authors of several countries and areas were invited to submit papers to this journal, in this special issue.

These papers are presented in this issue. The editors in charge of this work were Engineers Pascoal Bordignon and José Herbert Dolabela da Silveira and Professor Ronaldo Barbosa.

We thank once again $A B M$ technical staff for their tireless efforts, without which this editorship work would not have been possible.

We wish all a pleasant reading.

André Luiz Vasconcellos da Costa e Silva

Editor-in-chief

Universidade Federal Fluminense, Rio de Janeiro, RJ, Brasil

Editors of the Special Issue

José Herbert Dolabela da Silveira

Metallurgical Engineer, ABM Forming Technical Commission

Pascoal José Peixoto Bordignon

Metallurgical Engineer, Chairman of the IIth International Rolling Conference

Prof. Dr. Ronaldo Antônio Neves Marques Barbosa

Mechanical Engineer, Chairman of the scientific committee of the IIth International Rolling Conference

2176-1523 (c) 2020. Costa e Silva et al. Published by ABM. This is an Open Access article distributed under the terms of the Creative Commons Attribution License, which permits unrestricted use, distribution, and reproduction in any medium, provided the original work is properly cited. 